manometer, one shortly after the other. One reading was taken at a low wire temperature and the other at a higher wire temperature. The manometer had previously been calibrated at both of these temperatures. The pressure corresponding to the resistance at the higher temperature was $0.00078 \mathrm{~mm}$., according to the calibration curve. That corresponding to the resistance at the lower temperature was "negative" and equal to $-0.002 \mathrm{~mm}$. These two readings showed that there was an increase of resistance of about $0.12 \mathrm{ohms}$ more than the zero-pressure resistance and that the temperature coefficient of resistance was lower than the temperature coefficient of the wire when calibrated. The hypothesis that the active hydrogen is absorbed by the platinum therefore seems justified.

Although the experimental evidence is hardly conclusive, we feel that the abnormalities observed when a Hale-Pirani manometer is used with a tungsten lamp can best be explained by assuming that atomic hydrogen is produced in the burning lamp and that this hydrogen alloys with the platinum of the manometer, increasing its resistance. The writer hopes to be able to conclusively prove this point at a later date.

Research Labor.atory General Electric Co., SCHENECTADY, N. Y.

\title{
CHEMICAL REACTIONS AT VERY LOW PRESSURES. II. THE CHEMICAL CLEAN-UP OF NITROGEN IN A TUNGSTEN LAMP. ${ }^{\prime}$
}

BY IRVING LAXGMUJR.

Received June 6, 1913.

It has been previously shown ${ }^{2}$ that small amounts of hydrogen introduced into a tungsten lamp with heated filament will slowly disappear. Subsequently, a careful study was made of the kinetics of the reaction between a hot tungsten wire and oxygen at low pressure. ${ }^{3}$

The object of the present paper is to record some observations made during a detailed study of the behavior of nitrogen in tungsten lamps.

In the manufacture of tungsten filaments it was long the common practice to thoroughly sinter the filament by electrically heating it to a very high temperature in an atmosphere consisting largely of hydrogen. Originally pure hydrogen was used; subsequently, to avoid dangerous explosions and to reduce cost, mixtures of nitrogen and hydrogen were employed. Both of these gases appeared to be completely inert towards the metallic tungsten, even at temperatures close to the melting point of the filament.

The power required to maintain a tungsten wire at high temperatures in nitrogen at atmospheric pressure was determined, and it was thus

${ }^{1}$ Paper read before the New York Section of the American Chemical Society, Nov. 8,1912 .

2 This Jolrnal, 34, I3Io (IgI2).

${ }^{3}$ Ibid., 35, 105 (1913). 
found that the heat conductivity of nitrogen varies with the temperature in the normal way. From this it was concluded that nitrogen was not perceptibly dissociated into atoms even at temperatures as high as $3500^{\circ} \mathrm{K}$.

It has often been observed that low pressures of nitrogen in a lighted tungsten lamp gradually clean up. This was generally considered to be an electrical effect, as it was commonly accompanied by a flash of blue or purple glow and had been found to take place much more readily with high voltage lamps. Some early experiments showed that part, at least, of this nitrogen could be recovered as such by heating the bulb.

Mr. G. M. J. Mackay, of this laboratory, found that even in low-voltage tungsten lamps nitrogen cleans up. The rate is extremely slow with filaments at $2400^{\circ} \mathrm{K}$., taking several hundred hours for a cubic centimeter to clean up, but it increases greatly at higher temperature. Simultaneously, a brownish deposit appears on the bulb instead of the usual black deposit of tungsten. Upon opening the lamp and letting in moist air, the brown color gradually changes to a muddy gray and a smell of ammonia can be observed. There is thus strong evidence that the tungsten combines with the nitrogen to form a brown-colored nitride. The question at once arose, why, at very high temperatures and at atmospheric pressures, does not nitrogen attack the tungsten filament appreciably?

The whole subject of the clean-up of nitrogen in tungsten lamps was therefore investigated. It was soon found that there are three distinct ways in which the nitrogen may disappear:

I. Chemically. -The nitrogen combines with tungsten vapor (not with solid tungsten) to form the brown compound $\mathrm{WN}_{2}$. No fatigue effect can be detected.

2. Electrochemically.--If an electric discharge passes through nitrogen and a hot tungsten cathode is used, the nitrogen combines with tungsten to form the nitride $\mathrm{WN}_{2}$. No fatigue is apparent.

3. Electrically. - At very low pressures and high voltages there seems to be a reversible clean-up of limited quantities of nitrogen, in which the nitrogen is driven on to the glass in such a form that it can be recovered by heating. There are very marked fatigue effects.

In the present paper only the chemical clean-up of nitrogen will be described. The other two kinds of clean-up will be treated in subsequent papers.

\section{Chemical Clean-up of Nitrogen.}

The chemical clean-up of nitrogen is best observed when a short piece of tungsten wire is heated to a temperature of $2700^{\circ} \mathrm{K}$., or more, in nitrogen at pressures below $0.1 \mathrm{~mm}$. The length of the filament must be such that the voltage required to heat the filaments will be less than 40 volts; otherwise the effects are complicated by the electrochemical clean-up.

1 Thrs Journal, 34, 860 (IgI2). 
If the pressure is measured at regular intervals by means of a McLeod gage, it is found that the nitrogen disappears at a constant rate, so long as the filament is maintained at a constant temperature. That is, the rate of clean-up is independent of the pressure of the nitrogen.

Figs. I and 2 give the results of two typical experiments of this kind. The curve in Fig. I shows that the pressure decreases linearly with the

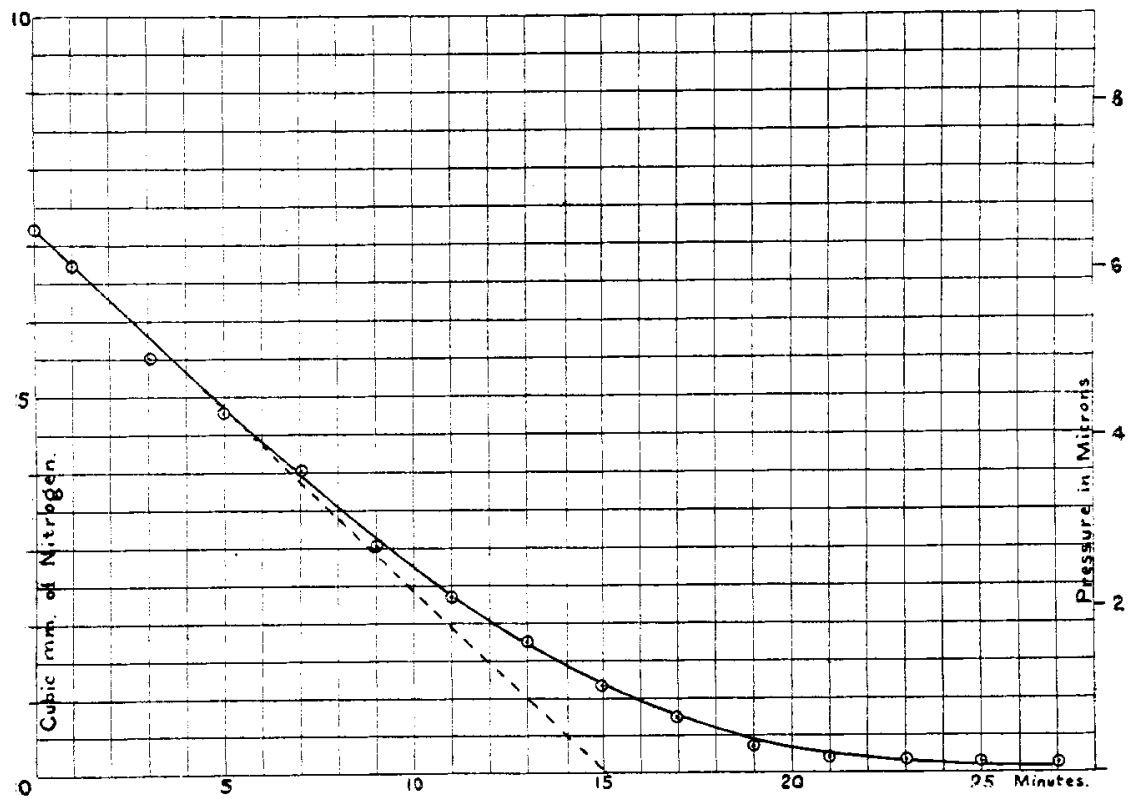

FIG. I-Rate of clean-up of nitrogen. Tungsten wire $36.8 \mathrm{~cm}$. long and $0.00 \mathrm{jz}$ $\mathrm{cm}$. diameter in cylindrical bulb $9 \mathrm{~cm}$. diameter. Temperature of filament, $2675^{\circ} \mathrm{K}$. Points experimentally derermined. Curve calculated from equation (9) taking $S=$ 0.000435 and $c=550$.

time, until the pressure becomes as low as about two or three microns. Fig. 2 shows the results of a run at higher pressures. In this case the heating of the gas by the filament causes an initial expansion, and after the current is turned off the filament there is a corresponding decrease in pressure as the bulb and gas cool again to room temperature. At low pressures, as may be predicted from the kinetic theory, these effects are much smaller. In calculating the rate of clean-up in this second run, the total decrease in the quantity of nitrogen (i. e., I47-Io8, or $39 \mathrm{cu} . \mathrm{mm}$.) is divided by the time during which the filament was actually lighted (i. e., ro8 minutes).

In Table $I$ is a summary of the results of experiments with pressures of nitrogen of $0.1 \mathrm{~mm}$. and less. The rates of clean-up were determined from readings of the McLeod gage. 
TABLE I.

Expt. $28 \mathrm{I}$.

Filament diameter, $0.00710 \mathrm{~cm}$; filament length, $36.8 \mathrm{~cm}$; filament effective area, 0.78 sq. cm.

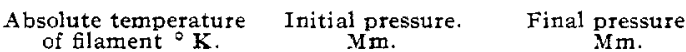
$2675 \quad 0.0065$ $0.000 \mathrm{I}$

Rate of clean-up cu. min, per min. per sq. cm.

0.62

Exp. 291.

Filament diameter, $0.0129 \mathrm{~cm}$; f flament length, $17.9 \mathrm{~cm}$; filament effective area, $0.67 \mathrm{sq} . \mathrm{cm}$.

$\begin{array}{cccc}\begin{array}{c}\text { Absolute temperature } \\ \text { of filament }\end{array} & \text { Initial pressure. } & \text { Final pressure. } & \begin{array}{c}\text { Rate of clean-up } \\ \text { cu. mm. per min. } \\ \text { per sq. cm. }\end{array} \\ 2640 & 0.060 & 0.045 & 0.5 I \\ 2745 & 0.112 & 0.082 & 1.58 \\ 2745 & 0.108 & 0.096 & 2.06 \\ 2790 & 0.032 & 0.023 & 2.30 \\ 2820 & 0.082 & 0.060 & 4.18\end{array}$

The temperatures were determined indirectly from the formula:

$$
\Gamma=\frac{1 \mathrm{I} 230}{7.029-\log \mathrm{H}} .
$$

Here $\mathrm{H}$ is the intrinsic brilliancy of the filament in international candle

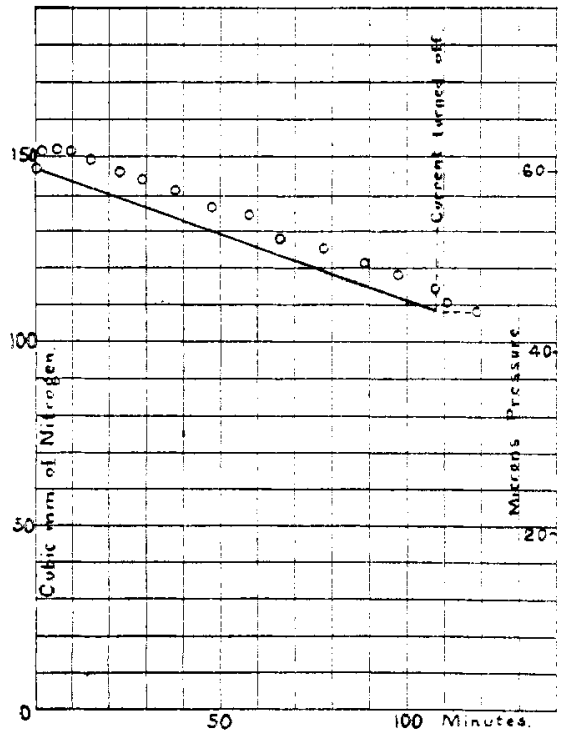

Fig. 2.- Rate of clean-up of nitrogen with through the filament. a tungsten wire $17.9 \mathrm{~cm}$. long, and 0.0129 $\mathrm{cm}$. diameter, at a temperature of $2640^{\circ} \mathrm{K}$.

1 The derivation of this formula, together with other methods of obtaining the temperature of filaments, will soon be published, probably in the Physical Review. power per sq. cm. (projected area). ${ }^{1}$ Actually, however, in these lowpressure experiments, since it was inconvenient to photometer the lamps connected to the vacuum system, the temperatures were obtained. from the current used to heat the filament. From data at hand in this laboratory (based originally on candle power measurements) the temperature can then be calculated for a wire of any given diameter.

During an experiment, as the diameter of the filament gradually became smaller by evaporation, the temperature was maintained constant by keeping $\mathrm{V}^{3} \sqrt{\mathrm{A}}$ constant, where $\mathrm{V}=$ voltage and $\mathrm{A}=$ current

With pressures of nitrogen as low as o.f $\mathrm{mm}$. and at these high tem- 
peratures, the cooling of the filament by the gas is small-never more than about $20^{\circ}$.

In Table II are given the results of an experiment in which pressures of nitrogen ranging from o up to $\mathrm{I} \mathrm{mm}$. were used. Five low voltage lamps with single loop filaments were made up and exhausted in the regular way, but just before sealing off from the pump various pressures of pure dry nitrogen (0.044, 0. 190, 0.500 and $\mathrm{I} .00 \mathrm{~mm}$.) were introduced.

The lamps were photometered in the regular way and set up on life test at one watt per candle efficiency and maintained at constant voltage. At intervals of about Ioo hours they were photometered. There were several indications that the nitrogen was gradually cleaning up. In the first place the candle power in lamps 3,4 , and 5 gradually increased. while the current decreased. In lamp i the candle power decreased from the beginning. This change in candle power indicated that the temperature of the filament was increasing, owing to the removal of the nitrogen.

TABLE II.

Expt. 261 .

Bulbs, 2fo ce. capacity; filaments diameter, $0.0129 \mathrm{~cm}$; length, $12.0 \mathrm{~cm}$; surface, $0.48 \mathrm{sq}$. cm.

$\begin{array}{cc} & \begin{array}{c}\text { Pressure. } \\ \text { Mm. }\end{array} \\ 1 & 0.00 \\ 2 & 0.04+ \\ 3 & 0.190 \\ 4 & 0.500 \\ 5 & 1.00\end{array}$

\begin{tabular}{lc}
\multicolumn{2}{c}{ Orig. characteri } \\
Volts. & Amps. \\
I5.15 & 2.20 \\
15.4 & 2.27 \\
15.5 & 2.31 \\
I6.0 & 2.37 \\
18.1 & 2.27
\end{tabular}

$\begin{array}{lc}\text { C. P. } & \begin{array}{c}\text { Temp. } \\ 33.5\end{array} \\ 34.8 & 2430 \\ 36.0 & 2438 \\ 38.0 & 2447 \\ 41.2 & 2465\end{array}$

$\begin{array}{rcc}\begin{array}{c}\text { V. } \\ \text { IIm. }\end{array} & \begin{array}{c}\text { Time to } \\ \text { clean-up. } \\ \text { Hrs. }\end{array} & \begin{array}{c}\text { Rate of } \\ \text { clean-up. }\end{array} \\ 0 & \ldots & \ldots \ldots \\ 1+ & \ldots & \ldots \ldots \\ 60 & 200 & 0.0107 \\ 158 & 350 & 0.0160 \\ 316 & 1000 & 0.0113\end{array}$

Secondly, the deposit which gradually accumulated on the bulbs of all the lamps was black in lamps $I$ and 2, and pure brown in the others. However, after about 300 hours, the deposit on No. 3 also began to be black. In No. 4 the brown became somewhat grayish after 500 or 600 hours, while in No. 5 the bulb remained clear bro nn until the end of its life-roog hours.

A third indication of the clean-up of nitrogen w is obtained by testing the lamps with a spark coil, as is the custom in the nanufacture of lamps. From the character of the discharge, it was found hat the vacuum gradually improved and finally, in all but lamp 5, bec เme nearly as good as the vacuum lamps.

The temperatures in this experiment were calculated from the candle power directly, first, however, making correction (about $12 \%$ ) in the can. dle power, because of the cooling effect of the leading-in wires. In Table II, $q$ is the quantity of nitrogen in the bulb, expressed in cubic mm. at atmospheric pressure.

The "time to clean-up" is the time at which the spark-coil test first 
indicated a fairly good vacuum. These results are only very approximate.

The rate of clean-up is expressed as before, in cubic mm. of nitrogen per min. per sq. $\mathrm{cm}$. of filament surface.

We see from the above data that the chemical clean-up of nitrogen takes place very slowly indeed, with filaments at their ordinary operating temperature. It is only at very high temperatures that the rates become so large that they can be measured in intervals of a few hours or minutes. Under such conditions the life of the filament itself is rather short, due to its evaporation, and it is of interest to determin whether there is a definit relation between the amount of tungsten evaporated and the quantity of nitrogen that disappears.

For this reason and also for the intrinsic interest of the subject, a careful investigation of the rate of evaporation of tungsten at various temperatures was made.

The results of this work will soon be published in detail. A preliminary statement will be of interest here.

\section{Rate of Evaporation and Vapor Tension of Tungsten.}

It will be shown that the rate of evaporation $M$ of tungsten in vacuum (in grams per sq. $\mathrm{cm}$. per second) is given by the equation:

$$
\log M=I 5.402-\frac{47444}{T}-I .4 \log T \text {. }
$$

From this the vapor pressure of tungsten (in mm.) can be calculated, and is found to be

$$
\log p=15.502-\frac{47444}{T}-0.9 \log T .
$$

The latent heat of evaporation (in gram calories per gram atom) at the temperature $T$ is then

$$
\lambda=2 \mathrm{I} 8000-\mathrm{I} .8 \mathrm{~T} \text { g. calories. }
$$

From equation (3) the boiling point of tungsten would be $5110^{\circ} \mathrm{K}$. This, however, does not take into account the latent heat of fusion. The most probable value of the boiling is therefore in the neighborhood of $5000^{\circ} \mathrm{K}$.

At the melting point $\left(3540^{\circ} \mathrm{K}\right)$ the vapor pressure is $0.080 \mathrm{~mm}$. At $2400^{\circ} \mathrm{K}$, the temperatures of the filaments of ordinary lamps running at I watt per candle, the vapor pressure is $0.8 \times 10^{-9} \mathrm{~mm}$.

Knowing now the rate of evaporation of tungsten at various temperatures, we can test out the theory that the nitrogen combines with the tungsten vapor as fast as it is liberated from the filament. Let us assume provisionally that the nitrogen molecules combine directly with tungsten atoms to form the compound $\mathrm{WN}_{2}$. In this case we calculate that I gram of tungsten will combine with $13 \mathrm{I}$ cc. of nitrogen at $20^{\circ}$ to form $\mathrm{WN}_{2}$. 
Hence the rate of clean-up of nitrogen (in cubic mm. per min. per sq. cm.) will be $7.86 \times 10^{6}$ times $M$. We thus obtain for $R$ the rate of clean-up of nitrogen:

$$
\log R=22.298-\frac{47444}{T}-I .4 \log T .
$$

To test out our hypothesis that the nitrogen combines with the tungsten vapor to form $W_{2}$, the value of $\mathrm{R}$ has been plotted (Fig. 3), together with the experimentally determined points taken from Tables $I$ and II.

The agreement is sufficiently good to prove that the temperature coefficient of the rate of clean-up of nitrogen is practically identical with that of the rate of evaporation of tungsten, and further that the ratio between the amount of nitrogen that disappears and the amount of tungsten that evaporates is practically equal to the ratio of nitrogen to tungsten in the compound $\mathrm{WN}_{2}$.

\section{Clean-up of Nitrogen at Higher Pressures.}

At pressures above I $\mathrm{mm}$. the rate of evaporation of tungsten is very materially reduced by the presence of nitrogen. At atmospheric pressure the rate is only a few per cent. of the rate in a

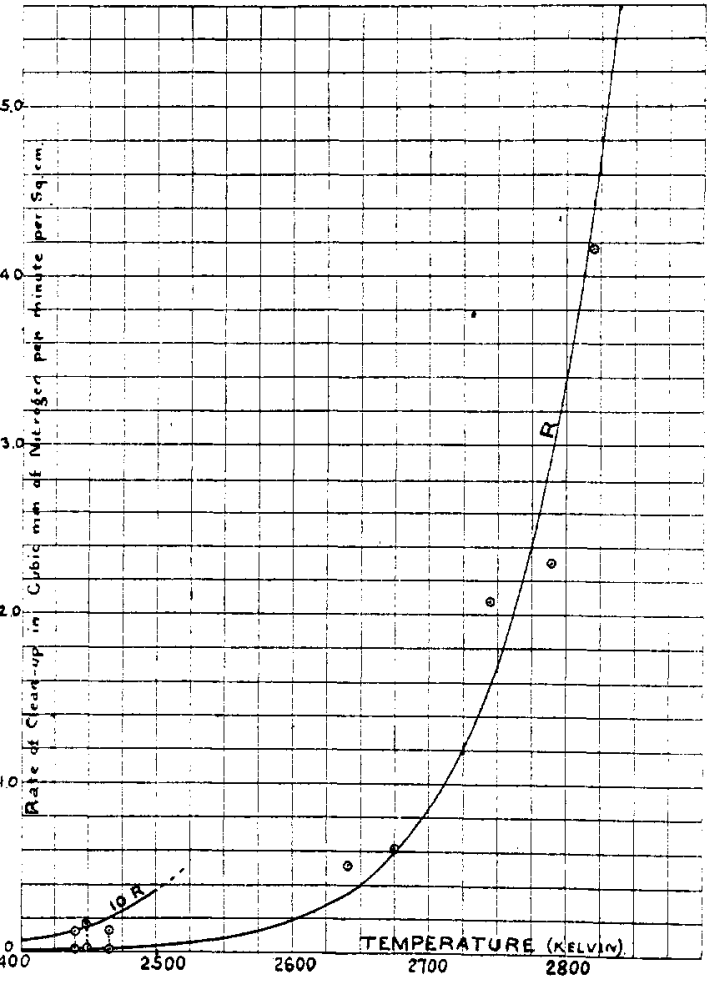

FIG. 3-Rate of clean-up of nitrogen as a function of the temperature. The points are experimentally determined. The curve is calculated by equation (5). vacuum or may even be much less than $r \%$ (varying according to the temperature). Even at atmospheric pressure, however, the tungsten which does evaporate deposits on the bulb in the form of the brown nitride. We may therefore conclude that the rate of clean-up is still proportional to the rate of evaporation. The rate of clean-up of nitrogen must then actually decrease as the pressure of nitrogen increases above one $\mathrm{mm}$.

The following is an example of an experiment at a higher pressure: 
A low-voltage lamp (No. 6025-5) was made up with a single loop filament $0.0239 \mathrm{~cm}$. diameter and $14.0 \mathrm{~cm}$. long. The bulb had a capacity of $570 \mathrm{cc}$. After a good exhaust, and before sealing off, nitrogen was admitted to a pressure of $20 \mathrm{~mm}$. The lamp was photometered at I watt per candle with the following results:

$$
\begin{aligned}
& \text { I6. I volts. } \\
& 6.6 \text { amps. } \\
& \text { I } 10.0 \text { candle power. }
\end{aligned}
$$

It was set up on life test at constant current (6.6 amps.). After $233^{\circ}$ hours it was taken off test and was found to have the following characteristics:

$$
\begin{aligned}
& 17.5 \text { volts. } \\
& 6.6 \text { amps. } \\
& 78.8 \text { candle power. }
\end{aligned}
$$

From the change in voltage $(8.7 \%)$ the decrease in diameter can be shown to be $2.9 \%$ and hence the loss in weight $5.8 \%$, or since the whole filament weighs $122 \mathrm{mg}$. the loss is $7.0 \mathrm{mg}$. This gives us for the rate of evaporation

$$
0.80 \times 10^{-9} \text { g. per sec. per sq. cm. }
$$

The temperature of the filament (from corrected candle power) as originally set up, was $2518^{\circ} \mathrm{K}$. During its life it gradually rose to $2578^{\circ}$. A weighted mean of these would be roughly $255^{\circ}$. If we calculate the rate of evaporation in vacuo from equation (2), we obtain

$$
\text { 10. } 5 \times 10^{-9} \mathrm{~g} \text {. per sec. per sq. } \mathrm{cm} \text {. }
$$

The presence of $20 \mathrm{~mm}$. of nitrogen thus cuts the rate of evaporation down to $7.5 \%$ of what it would be in vacuo at the same temperature.

The total quantity of nitrogen introduced into the bulb was

$$
\frac{20}{760} \times 570=I_{5} \mathrm{cc} \text {. }
$$

After taking the lampoff test, the tip of the bulb was broken under mercury and the amount of residual gas found to be about i $4 \mathrm{cc}$. Only about I cc. had been used up. The chemical equivalent of the $7 \mathrm{mg}$. of $\mathrm{W}$ which evaporated from the filament, on the basis of $\mathrm{WN}_{2}$, would be $0.9 \mathrm{cc}$., which agrees well with that observed. If we calculate, however, the rate of clean-up from equation (4), or in other words calculate the chemical equivalent of the tungsten that would have evaporated in vacuo in $233^{\circ}$ hours at $2550^{\circ}$, we obtain $\mathrm{r} 2 . \mathrm{Cc}$., very different from the observed clean-up.

We thus see that at a pressure of $20 \mathrm{~mm}$. both the rate of evaporation and the rate of clean-up are cut down to about $8 \%$ by the presence of the nitrogen.

\section{Discussion of Results.}

The experiments clearly indicate that nitrogen is chemically inert towards solid tungsten, but combines with tungsten vapor as fast as this 
is given off by the solid metal to form the brown compound $\mathrm{WN}_{2}$. This compound is readily decomposed by water to form $\mathrm{NH}_{3}$ and probably $\mathrm{WO}_{3}$. It appears to be stable in a vacuum up to at least $400^{\circ}$, as no change in color occurs on heating a bulb covered with the nitride up to the softening point of the glass, nor is there any evolution of nitrogen produced by such heating.

The application of the principles of the kinetic theory enables us to draw several interesting conclusions as to the mechanism of the reaction.

The Theory of the Clean-up at Very Low Pressures.

The average free path of the molecules in nitrogen at atmospheric pressure is about $9.5 \times 10^{-8} \mathrm{~cm}$. At a pressure of $0.001 \mathrm{~mm}$. the normal free path would thus be 760,000 times greater, or $7.2 \mathrm{~cm}$.

The free path $L_{1}$ of a tungsten atom in nitrogen would be greater than this. If $L_{2}$ is the normal free path of a nitrogen molecule, then from the relative atomic volumes of tungsten and nitrogen the mean free path of a tungsten atom in nitrogen can be shown to be

$$
\mathrm{L}_{1}=\mathrm{I}_{2} \frac{2.09}{\sqrt{\mathrm{I}+6.6 \frac{\mathrm{T}_{2}}{\mathrm{~T}_{1}}}}
$$

where $T_{2}$ is the temperature of the nitrogen and $T_{1}$ that of the tungsten. Thus for a filament at $2700^{\circ}$ in nitrogen at $300^{\circ}$ and $0.001 \mathrm{~mm}$. pressure, we have

$$
L_{1}=I .59, L_{2}=I I .4 \mathrm{~cm} .
$$

The bulb used in Expt. 28I was approximately the shape of a cylinder $9 \mathrm{~cm}$. in diameter, about $15 \mathrm{~cm}$. long, with rounded ends. The filament was in the form of two loops placed very close to the axis of the cylinder. The minimum distance from the filament to the inner surface of the bulb was about $3.5 \mathrm{~cm}$. The average distance traversed by a tungsten atom before striking the bulb was naturally considerably greater than this, since many of the atoms would have large components of their paths parallel to the axis of the bulb. As a first approximation, let us assume, however, that the average distance from the bulb to the filament is $6 \mathrm{~cm}$. This is only $53 \%$ of the average free path of tungsten in nitrogen at $0.00 \mathrm{Imm}$. pressure.

According to Meyer's Kinetic Theory of Gases, the fraction of the molecules which travel a distance more than $q$ times the average free path without colliding is given by the expression $e^{-q}$. From this we calculate that at $0.00 \mathrm{Imm}$. pressure, about $59 \%$ of the tungsten atoms pass from the filament to the bulb without striking nitrogen molecules on the way, and therefore without opportunity of combining with the nitrogen. We therefore conclude that at a pressure of $0.00 \mathrm{~mm}$. the rate of clean-up of nitrogen is only about $41 \%$ of that at say 0.01 
mm., at which pressure practically all of the tungsten atoms collide with nitrogen molecules before reaching the bulb.

We see from Fig. I that the rate at $0.00 \mathrm{Im}$. pressure is actually somewhere in the neighborhood of $41 \%$-as great as at higher pressures. To test out these conclusions quantitatively, let us calculate the shape of the theoretical curve giving the relation between the pressure and the time, assuming that a certain proportion of the tungsten atoms go to the bulb without colliding and that all those that do collide with nitrogen molectles combine with them.

Let $p=$ pressure at time $t$.

$\mathrm{S}=$ rate of clean-up in cu. mm. per min, at such high pressures that none of the tungsten atoms reach the bulb without first colliding with nitrogen molecules, but at sufficiently low pressures that the rate of evaporation of the tungsten is not appreciably decreased by the presence of the nitrogen.

$\mathrm{L}=$ average free path at the pressure $p$ (in very large bulb).

$b=$ average distance a tungsten atom must travel from filament before reaching the bulb, with pressures so low that it does not collide with nitrogen molecules.

$c=\frac{b}{\mathrm{~L} p}=$ constant since $\mathrm{L}$ is inversely proportional to $p$.

If the pressure is such that all the tungsten atoms collide with nitrogen molecules before reaching the bulb, then we have

$$
\frac{d p}{d t}=-\mathrm{S}
$$

But at lower pressures the fractions $e^{-b / L}$ reach the bulb without colliding. Hence the rate of clean-up would be

$$
\frac{d p}{d t}=-\mathrm{S}\left(\mathrm{I}-e^{-b / \mathrm{L}}\right)
$$

or, since

$$
\begin{gathered}
b=c p, \\
\mathrm{~L}=c c_{1} \\
\frac{d p}{d t}=-\mathrm{S}\left(\mathbf{I}-e^{-c p}\right) .
\end{gathered}
$$

If we integrate this and impose the condition that the pressure is $p_{0}$ when $t=0$, we obtain

$$
\mathrm{S} t=p_{0}-p+\frac{\mathrm{I}}{c} \ln \frac{\mathrm{I}-e^{-c p_{0}}}{\mathrm{I}-e^{-c b}} .
$$

This equation gives us the pressure as a function of the time, at pressures so low that part of the tungsten goes directly to the bulb.

By trial, values of the constants $S$ and $c$ were calculated which would give the closest agreement with the experimentally determined points in Fig. I. These values are 


$$
\begin{aligned}
\mathrm{S} & =0.000435 \mathrm{cu} . \mathrm{mm} \text {. per min. } \\
c & =650 .
\end{aligned}
$$

These were substituted in equation (9) and $t$ and $p$ were calculated, taking $p_{0}=0.0065$. From the values of $p$ the quantity of gas in cubic mm. was obtained by multiplying by the ratio $\frac{7.1}{0.0065}$. In this way the curve drawn in on Fig. I was obtained. It is seen that the agreement is good; in fact, within the experimental error.

This calculation gives us, then, an experimentally determined value of $c$ from which we can calculate $b$, the average distance that the tungsten atoms must travel before they are deposited on the bulb. For a pressure of $0.00 \mathrm{Imm}$. $I=I 1.4$, and hence from the definition of $c$ we have

$$
b=c \mathrm{~L} p=7.4 \mathrm{~cm} \text {. }
$$

Since the minimum distance from filament to bulb is $3.5 \mathrm{~cm}$., we see that the above result is entirely reasonable. It leads us with considerable certainty to the following conception of the mechanism of the reaction:

I. Practically every collision between a free tungsten atom and a free nitrogen molecule results in chemical combination.

2. The tungsten atoms which reach the bulb do not react with nitrogen adsorbed on the bulb, nor with any nitrogen molecules which subsequently strike the bulb. They deposit on the bulb as metallic tungsten.

3. It is not necessary that the nitrogen shall have been previously activated by the filament in order that combination shall take place. In other words, dissociation or ionization of the nitrogen is not necessary for this reaction.

4. Only one collision is necessary for the formation of the brown nitride. The compound is therefore formed by the direct union of a tungsten atom with a nitrogen molecule, and hence its molecule contains two atoms of nitrogen. It must also contain only one atom of tungsten, unless one could assume that the tungsten evaporated in the form of molecules $\mathrm{W}_{2}$ or $\mathrm{W}_{3}$, etc. The fact that the ratio of the quantity of tungsten evaporated to the amount of nitrogen cleaned up indicates the composition $\mathrm{WN}_{2}$, would therefore indicate that tungsten vapor is monatomic.

Theory of the Clean-up at Pressures above I $\mathrm{mm}$.

As we have seen, the clean-up at pressures above $0.003 \mathrm{~mm}$. and up to o. I $\mathrm{mm}$. is practically independent of the pressure. This indicates that the rate of evaporation of tungsten is unaffected by such low pressures of gas. At $20 \mathrm{~mm}$. pressures and still more at atmospheric pressure, the rate of evaporation is greatly reduced. Both these facts are in complete agreement with the kinetic theory.

We may safely assume that the real rate at which the tungsten atoms leave the surface of the metal is practically independent of the pressure, 
even up to atmospheric pressure. At such high pressures, however, a very large proportion of the atoms return again to the filament.

It is evident that with pressures so low that the free path of the tungsten atoms is larger than the diameter of the filament, relatively very few tungsten atoms return to the filament. At such low pressures, therefore, the rate of evaporation is not greatly affected by the gas.

On the other hand, when the free path of the tungster atoms is much less than the diameter of the filament, then the chance of the atoms coming back again to the filament becomes very great and the rate of evaporation is considerably reduced, provided the nitride is unstable at the temperature of the filament.

At such high pressures that the free path is an extremely small fraction of the diameter of the filament, we may then consider evaporation to be simply a diffusion phenomenon in which tungsten vapor (or the nitride) diffuses through a layer of definit thickness (at atmospheric pressure of a couple of millimeters) of nitrogen. If we knew the diffusion coefficient, the rate of evaporation could then be calculated. However, the tungsten vapor (or nitride) in presence of a gas, probably does not long remain as a monatomic vapor, or single molecules of the nitride, but rapidly forms groups of atoms, or dust particles. The size of these particles will depend on the partial pressure of the tungsten vapor, and hence on the temperature. At lower temperatures the tungsten atoms will be relatively so far apart that they find no opportunity of combining together. At high temperatures they form larger particles. The rate of diffusion depends to a great extent on the size of the particles, and it becomes very probable that the diffusion coefficient at high temperatures is much less than at lower temperatures. This conclusion is confirmed by rough experiments. Quantitative measurements of the rate of evaporation at various pressures and at different temperatures are being made and will probably form the basis of a future publication.

The fact that even at atmospheric pressures of nitrogen the deposit on the bulb consists of the nitride and not metallic tungsten, indicates that the tungsten vapor combines with the nitrogen before it forms dust particles. The particles, therefore, consist of the nitride. It also indicates that the nitride is decomposed into nitrogen and tungsten when it diffuses back to the hot filament.

The criterion, as we have seen, as to whether the presence of a gas will materially diminish the rate of evaporation, is whether or not the free path of the tungsten atoms is much greater than the diameter of the filament. At one mm. pressure the free path is $0.0114 \mathrm{~cm}$. Therefore, for a filament of $0.007 \mathrm{~cm}$. diameter, the pressure at which the free path would equal the diameter of the filament is $\frac{0.01 \mathrm{II}}{0.007}$, or $1.6 \mathrm{~mm}$. Hence, we 
should expect, between the pressures of 0.003 and about $\mathrm{I} \mathrm{mm}$, that the clean-up of nitrogen would be practically independent of the pressure, but above about one or two $\mathrm{mm}$. pressure, the rate would very materially decrease. The experiments bear out this conclusion in a general way.

Soddy ${ }^{1}$ found that calcium vapor reacted with all gases except the group of inert gases, whereas solid calcium reacted only slowly, if at all. In the case of calcium, the simplest explanation would seem to be that the metallic calcium becomes coated with a layer of the compound, which thus limits the rate of reaction. The present work with tungsten and nitrogen suggests that the reaction, even without a coated surface, would perhaps take place only between the vapor and the gas.

In conclusion, it should be pointed out that this type of reaction appears to be a common one among metals heated to high temperatures in gases. The writer has found that the behavior of platinum in oxygen at low pressures is exactly analogous to that of tungsten in nitrogen. In this case the oxygen does not perceptibly attack the platinum, but combines with the platinum vapor as fast as this is given off by the wire to form the compound $\mathrm{PtO}_{2}$. The rate of loss of weight of the platinum in vacuum and in oxygen at low pressures is identical, and the rate of clean-up of the oxygen is independent of the pressure. These results will soon be published in detail, as will also data on the vapor pressures and rate of evaporation of platinum.

\section{Summary.}

I. Nitrogen in a lighted tungsten lamp disappears in three ways:

Chemically, Electrochemically, Electrically.

2. The chemical clean-up depends on the combination of the nitrogen with tungsten vapor, to form the brown compound $\mathrm{WN}_{2}$.

3. From zero pressure up to about $0.001 \mathrm{~mm}$., the rate of chemical clean-up is proportional to the product of the rate of evaporation and the pressure of nitrogen.

4. From about $0.003 \mathrm{~mm}$. up to about $\mathrm{I} \mathrm{mm}$., the rate is directly proportional to the rate of evaporation and independent of the pressure.

5. At pressures above $2 \mathrm{~mm}$., the rate of clean-up is still directly proportional to the rate of evaporation, but the rate of evaporation is materially reduced by the presence of the gas.

6. Nitrogen does not, at any temperature, react perceptibly with solid tungsten.

7. The rate of evaporation of tungsten in vacuo at any temperature $\mathrm{T}$ (Kelvin) is given by the equation

' Proc. Roy. Soc., 78, 429 (1907). 


$$
\log _{10} \mathrm{M}=15.402-\frac{47444}{\mathrm{~T}}-\mathrm{I} .4 \log _{10} \mathrm{~T}
$$

where $M$ is expressed in grams of tungsten per second per sq. cm. of surface.

8. The vapor pressure of tungsten in $\mathrm{mm}$. of mercury is given by the equation

$$
\log _{10} p=\mathrm{I} 5.502-\frac{47444}{\mathrm{~T}}-0.9 \log _{10} \mathrm{~T} \text {. }
$$

9. The heat of evaporation is very high, namely:

$$
\lambda=2 \mathrm{I} 8,000-\mathrm{I} .8 \mathrm{~T}
$$

gram calories per gram atom.

Io. The vapor pressure of tungsten at its melting point $\left(3540^{\circ} \mathrm{K}\right)$ is $0.080 \mathrm{~mm}$. The boiling point of tungsten is in the neighborhood of $5000^{\circ} \mathrm{K}$.

I I. The following can be said of the mechanism of the reaction:

The tungsten vapor given off by the filament is monatomic. Each and every atom of the tungsten vapor, when it collides with a nitrogen molecule, reacts with it to form $\mathrm{WN}_{2}$. The nitrogen does not need to be dissociated or ionized before reacting with the tungsten vapor.

Tungsten atoms which strike the bulb do not react with a layer of adsorbed nitrogen if such is present. This may perhaps be taken to indicate that under the conditions of these experiments there is no such layer.

I2. The compound $\mathrm{WN}_{2}$ in thin layers is a clear, brown color, very different from finely divided tungsten. It is decomposed by water to form ammonia and probably $\mathrm{WO}_{3}$. It is stable in a vacuum at $400^{\circ} \mathrm{C}$., but is decomposed at a temperature of $2400^{\circ} \mathrm{K}$.

I3. The electrochemical clean-up of nitrogen takes place at much lower temperatures $\left(1900^{\circ} \mathrm{K}\right.$ ) than the chemical, when potentials much over 40 volts are used in a way which causes a perceptible discharge through the gas. No fatigue effect occurs and the nitrogen in this case combines with tungsten to form $\mathrm{WN}_{2}$.

14. The electrical clean-up occurs at pressures of $0.005 \mathrm{~mm}$. and less with 250 volts voltage and high filament temperatures. It is very erratic and shows marked fatigue effects, sometimes with alternate evolution and clean-up of nitrogen as the temperature or voltage is varied. Part, at least, of the nitrogen is easily recovered by heating the bulb.

I5. The behavior of platinum towards oxygen is in every way analogous to the behavior of tungsten towards nitrogen. In this case, oxygen at low pressures combines with platinum vapor to form $\mathrm{PtO}_{2}$, but does not attack solid platinum.

In subsequent papers, the following subjects will be treated in more detail: 
The vapor pressure of tungsten.

The vapor pressure of platinum.

The determination of the temperature of tungsten filaments.

The reaction between oxygen and platinum.

Two new kinds of hydrogen clean-up.

The electrochemical and electrical clean-up of nitrogen.

The dissociation of oxygen into atoms.

The writer wishes to express his indebtedness to Mr. G. M. J. Mackay and to Mr. S. P. Sweetser for very great assistance in carrying out this work.

Restarch laboratory, General Electric Company, SCHENECTADY, N, Y.

\section{NEW DESIGNS FOR SPECIFIC HEAT APPARATUS.}

By ARden R. JOHNSON AND BERnARd W. HAMMER.

Received June 10, 1913.

In the prosecution of an investigation of the specific heats of milk and milk derivatives recently carried out at Iowa State College it was found necessary to work out a design of a specific heat apparatus of simple construction which would lend itself to the attaining of results very rapidly, as well as accurately. Two designs have been evolved. In both the electric current is used for heating, but with one a variable voltage may be used, while with the other a very constant voltage is necessary.

\section{Apparatus No. I, for Variable Voltage.}

The outer insulating walls ( $\mathrm{I}$ ) of the apparatus consist of pressed cork, such as is used in the construction of refrigerators and thermostats. In the cylindrical cavity (2), which may be gouged out with a sharp paring knife, is the copper (or glass) calorimeter vessel (3) (Diam. $=6.25 \mathrm{~cm}$. Height $=8.75 \mathrm{~cm}$.) for holding Ioo grams of sample. (4) is another copper vessel $(\mathrm{D} .=4.7 \mathrm{~cm} ., \mathrm{H} .=8 . \mathrm{I} \mathrm{cm}$.) with a capacity of 100 grams of water, in which is immersed an electric light bulb and a thermometer to which a stirrer is attached. The vessel is arranged with a tight-fitting cap having a bayonet catch. Leads from the electric lamp pass up through a fiber or glass tube (5) which also serves as. a handle for the whole vessel and its contents which we may call the "heater." The upper portion (6) of the cork insulating vessel has cut through it a cylindrical hole just a trifle greater in diameter and deeper than the heater. Between the upper and lower portions of the cork container is a heavy asbestos board partition (7), the middle third of which is a slide that may be readily inserted or withdrawn.

The operation of the apparatus is as follows: Ioo grams of water are weighed in the vessel (3), which is placed in the cork thermostat. A 